\title{
ATIVIDADE, SIGNIFICAÇÃO E CONSTITUIÇÃO DO SUJEITO: CONSIDERAÇÕES À LUZ DA PSICOLOGIA HISTÓRICO-CULTURAL
}

Andréa Vieira Zanella

\begin{abstract}
RESUMO. É objetivo deste trabalho discutir conceitos da Psicologia Histórico-Cultural que se constituem como fundamentais para a explicação e investigação do processo de constituição psicológica do sujeito. Da concepção de ser humano, desenvolvimento e história, resgata-se a noção de ação mediada como fundante do psiquismo humano, o que atribui a este um caráter inexoravelmente social. À noção de ação mediada articula-se o conceito de atividade, o qual compreende ações, porém as transcende, na medida em que amplia, para o sujeito, as possibilidades de leitura e intervenção na realidade. A análise da atividade, por sua vez, pressupõe o olhar sobre as múltiplas relações que caracterizam a tríade sujeito/ações/contextos sociais, relações estas singulares e coletivas, na medida em que se pautam nas significações ali (re) produzidas, transformadas e apropriadas.
\end{abstract}

Palavras-chave: atividade; significação; constituição do sujeito.

\section{ACTIVITY, MEANING AND CONSTITUTION OF THE SUBJECT: REFLECTIONS BASED ON HISTORICAL-CULTURAL PSYCHOLOGY}

\begin{abstract}
The objective of this work is to discuss concepts of Historical-Cultural Psychology considered essencial to explain the psychological constitution of the human being. From the conception of being human, its development and history, a notion of mediated action as the founder of human psyche is rescued, attributing to it an inexorably social character. To the notion of mediated action, a concept of activity is related, which correspond to action, but goes beyond that, as the different possibilities of readings and interference arise for the individual. The analysis of activity, presupposes a glance over the multiple relations that characterize the triad: social context, subject and action, which are based in the meanings here (re)produced, transformed and appropriated.
\end{abstract}

Key words: activity, meaning, constitution of the subject.

\section{INTRODUÇÃO}

A constituição do psiquismo humano foi temática central nos trabalhos do russo L. S. Vigotski (18961934). Preocupado com a explicação de como o ser humano constitui-se como capaz de produzir cultura, esse autor mergulhou na produção da Psicologia de seu tempo em busca de respostas a essa questão. $\mathrm{O}$ que encontrou, no entanto, foi uma ciência marcada pela diversidade de explicações que se caracterizavam por tendências materialistas mecanicistas ou subjetivistas, perdendo-se nessas a dimensão históricosocial que permitiria uma explicação não dicotômica da relação sujeito-sociedade (ver Luria, 1979; Rivière, 1985; Wertsch, 1988 ou o próprio Vigotski, 1996).

A questão fundamental, portanto, que nos permite compreender a teoria de Vigotski, é a concepção de ser humano que de certa forma atravessa todos os seus escritos e que necessariamente precisa ser levada em conta: consonante com o referencial marxista e o tomando por base, Vigotski entende a pessoa como "um agregado de relações sociais encarnadas num indivíduo" (Vigotski, 2000, p. 33). Compreender essa assertiva não é tarefa fácil, sendo que o artigo de Pino (2000) que discute o manuscrito de Vigotski "Psicologia Concreta do Homem" é precioso neste sentido. O que a assertiva demarca, em síntese, é a inexorável relação entre sujeito e sociedade. Só há sujeito porque constituído em contextos sociais, os quais, por sua vez, resultam da ação concreta de homens que coletivamente organizam o seu próprio viver.

* Docente do Departamento de Psicologia e do Programa de Pós-Graduação em Psicologia da UFSC, Doutora em Psicologia da Educação pela PUC-SP, bolsista de produtividade em pesquisa do CNPq. 
A segunda parte desta afirmação - a de que os contextos sociais resultam da ação humana - é relativamente aceita por diversas vertentes psicológicas, embora em geral marcada por uma compreensão do social como fenômeno da natureza, descolado tanto da história dessa própria natureza quanto de seus agentes produtores. No que se refere à constituição do sujeito, no entanto, a questão é mais complexa e constantemente negada. Isso porque a psicologia, enquanto ciência, tem historicamente produzido explicações sobre o psiquismo humano que o identificam com processos cerebrais ou, contrapondo-se a estas, teorias que se limitam a descrever as características deste psiquismo, posto que o consideram fenômeno de outra ordem ${ }^{1}$.

A partir da reflexão proposta por Vigotski sobre essa temática, a qual afirma a síntese entre aspectos fisiológicos e psicológicos e confere ao ser humano uma existência ao mesmo tempo biológica, psicológica, antropológica, histórica e essencialmente cultural, é objetivo deste trabalho discutir, através de resultados de algumas investigações, os conceitos de ação e atividade e suas implicações para pesquisas que investigam o processo de constituição do sujeito orientadas nos aportes teóricos da Psicologia Histórico-Cultural.

\section{PSIQUE HUMANA, ATIVIDADE, AÇÃO E SIGNIFICAÇÃO}

Aspectos fisiológicos e psíquicos de toda e qualquer atividade psicológica humana, a partir do referencial vigotskiano, são entendidos não como esferas dicotômicas que interagem, mas como instâncias de um mesmo e único processo histórico que os constitui e inexoravelmente os relaciona. Afirma Vigotski que:

(...)[a psique] é uma parte da própria natureza, ligada diretamente às funções da matéria altamente organizada de nosso cérebro. Assim como a própria natureza, não tem sido criada, pois tem surgido em um processo de desenvolvimento. Suas formas embrionárias estão presentes desde o princípio: na própria célula viva se mantêm as propriedades de mudar sob a influência de

\footnotetext{
Ao analisar as diferentes vertentes da psicologia, Vygotski (1991c e 1996) apontou como representantes do primeiro grupo os reflexologistas e, do segundo, os teóricos idealistas que defendiam a psicologia como ciência da alma.
}

ações externas e de reagir a elas. (Vigotski, 1991a, p. 99-100)

Esta citação de Vigotski aponta para questões fundamentais de seu arcabouço teórico, as quais serão aqui desenvolvidas de forma separada para destacar a complexidade do que o autor afirma. Todos os tópicos, no entanto, estão relacionados, não havendo razão outra para apresentá-los na seqüência proposta além da intenção didática:

1. A relação de unidade entre psíquico e natureza, ou melhor, entre psíquico e físiológico: ao explicar a origem do psiquismo humano, Vigotski caracterizou a relação entre o psicológico e o fisiológico não como identidade ${ }^{2}-$ o que pressupõe igualdade - mas sim como unidade, a qual pode ser entendida como "qualidade daquilo que não pode ser dividido"; "aquilo que, num conjunto, numa espécie, etc., forma um todo completo" (Ferreira, 1997, p. 1738).

Novamente dialogava com a psicologia de seu tempo, ou melhor, com uma vertente desta que, marcada pelos avanços da fisiologia de Setchenov (Rivière, 1985; Wertsch, 1988), procurava estabelecer uma relação direta, causal, entre o cérebro humano e as funções psicológicas superiores. Em oposição, Vigotski defendia que

(...) a tarefa fundamental da psicologia dialética consiste precisamente em descobrir a conexão significativa entre as partes e o todo, em saber considerar o processo psíquico em conexão orgânica nos limites de um processo integral mais complexo (Vigotski, 1996, p. 149).

2. A noção de que tanto a natureza como o social não são dados, pois resultam do processo histórico que os origina e transforma: a referência ao marxismo é clara nessa afirmação, a qual destaca a dimensão histórica da realidade, seja esta física/biológica ou social $^{3}$. Deste modo, natureza e social não são

2 “(...) assumir a unidade do psíquico e do físico reconhecendo, em primeiro lugar, que a psique surgiu em um determinado nível de desenvolvimento da matéria orgânica e, em segundo, que os processos psíquicos constituem uma parte inseparável de conjuntos mais complexos, fora dos quais não existem e portanto não podem ser estudados, não deve nos levar a identificar o psíquico com o físico" (Vigotski, 1991a, p. 100).

3 Quanto ao que se entende por social, Pino (2000, p. 61) esclarece que "o social ao qual Vigotski se refere especificamente é o social humano, cuja emergência, com maior razão que as formas animais de sociabilidade, tem de 
dados, há um movimento permanente que os produz e modifica, caracterizando-se tanto a natureza quanto a própria coletividade humana enquanto processo: "A história pode ser examinada sob dois aspectos: história da natureza e história dos homens. Os dois aspectos, contudo, não são separáveis; enquanto existirem homens, a história da natureza e a história dos homens se condicionarão reciprocamente" (Marx \& Engels, 1989, p. 23-24 - nota de rodapé).

Destaca-se aqui a dimensão materialista-histórica da teoria marxista: existe um mundo material que antecede à existência do próprio homem; este mundo, porém, uma vez conhecido/transformado pela ação humana, deixa de ser natureza em si para se transformar em natureza significada e, portanto, cognoscível.

3. A referência a processos de desenvolvimento: cabe a reflexão sobre este tópico para demarcar a especificidade da perspectiva de Vigotski, que a diferencia da maioria das teorias psicológicas que tratam do desenvolvimento humano. Partindo do pressuposto de que há algo em germe que, na interação com o meio, irá se desenvolver, essas teorias preocupam-se com "a identificação de capacidades ou habilidades que distingam etapas ou estágios do desenvolvimento" (Lyra \& Moura, 2000, p. 218).

Contrapondo-se a essas teorias, Vigotski ressignifica o conceito de desenvolvimento e o modo como este se processa, na medida em que considera que não há nada em germe, mas unicamente como resultado da atividade humana no contexto de relações sociais. Por sua vez,

(...) o desenvolvimento não se produz pela via de mudanças graduais, lentas, por uma acumulação de pequenas peculiaridades que produzem em seu conjunto e ao final alguma modificação importante. Já desde o princípio o desenvolvimento observado é de tipo revolucionário. Dito de outro modo, observamos a existência de mudanças bruscas e essenciais no próprio tipo de desenvolvimento, nas próprias forças motrizes do processo. E é bem sabido que a

ser explicada por princípios outros, e não os meramente naturais ou biológicos. As formas humanas de organização social, em que a sociabilidade natural se concretiza, são obra do homem e, como tal, obedecem a leis históricas que determinam as condições concretas de sua produção. É o caráter histórico dessa produção que define o social humano" (grifos do autor). coexistência de mudanças revolucionárias com as evolutivas não é indício que exclua a possibilidade de aplicar a esse processo o conceito de desenvolvimento. (Vigotski, 1991a, p. 156)

Vigotski trabalha, portanto, com a idéia de que todas as conquistas que garantem às pessoas sua condição de humanização resultam das complexas relações sociais em que se inserem e das quais ativamente participam. Essas conquistas, por sua vez, podem somar-se a tantas outras ou promover saltos qualitativos no modo como se apropriam da realidade e estabelecem essas relações ${ }^{4}$.

4. A ênfase às ações como motores do desenvolvimento: este último aspecto da citação de Vigotski, que aparece no início deste texto e tomamos como mote para a discussão aqui apresentada, merece especial atenção, pois, se bem observado, esteve presente em todos os tópicos anteriores. Trata-se, na verdade, de uma questão central que vem mobilizando pesquisadores que trabalham com as contribuições de teóricos russos, seja os que se orientam prioritariamente pelos escritos de L. S. Vigotski seja os que se apoiam em A. Leontiév.

Contemporâneos, estes dois autores tiveram suas obras marcadas pelos acontecimentos da Rússia pré e pós-revolucionária, os quais os aproximaram em um primeiro momento e depois os afastaram, entre outras razões devido ao dogmatismo estalinista que vigorou nas primeiras décadas do período soviético. Vigotski havia falecido quando as restrições e diretrizes impostas por Stalin às ciências se tornaram mais duras (faleceu em 1934), porém a obra de Leontiév sofreu as influências dessas mudanças, conforme observa Zinchenko (1998). Em decorrência, dois caminhos na psicologia soviética de orientação marxista são traçados: a Psicologia Histórico-Cultural de Vigotski e a Teoria da Atividade de Leontiév.

As diferenças e proximidades entre estes dois arcabouços teóricos vêm sendo discutidas por vários pesquisadores (Duarte, 2000; Wertsch, 1988;

4 O desenvolvimento deixou em Vigotski de ser sinônimo de maturação biológica para compreender a complexidade das relações sociais e os sujeitos que daí resultam. Desse modo, "em contraposição à idéia de desenvolvimento como processo paulatino, de evolução progressiva, de acumulação quantitativa, Vigotski o entendeu como um complexo processo cujos pontos nodais, de virada, estão constituídos pelas crises, momentos em que se produzem saltos qualitativos que modificam toda a estrutura das funções [psicológicas], suas inter-relações e vínculos" (Shuare, 1990, p. 74). 
Zinchenko, 1998; Neves, 1997), alguns posicionandose pelo acirramento das diferenças e outros pela aproximação dos dois sistemas teóricos. Embora não seja objetivo deste texto tratar dessa temática, resgataremos aqui as principais diferenças nas contribuições à psicologia de Vigotski e Leontiév apontadas por Zinchenko:

(...) para a psicologia histórico-cultural, o problema central foi e continua sendo a mediação da mente e da consciência. Para a teoria psicológica da atividade, o problema central era a orientação-objeto em ambas as atividades, interna e externa. É claro que na teoria psicológica da atividade a questão da mediação também apareceu, mas enquanto que para Vigotski a consciência era mediada pela cultura, para Leontiév a mente e a consciência eram mediadas por ferramentas e objetos (Zinchenko, 1998, p. 44).

Da forma como Zinchenko apresenta, as diferenças entre Leontiév e Vigotski podem ser facilmente questionadas: afinal, o que são ferramentas e objetos senão a própria cultura humana objetivada? Neste sentido, em ambos os autores a questão da mediação cultural da consciência está posta, embora em Vigotski assuma lugar central na explicação sobre a constituição dos processos psicológicos caracteristicamente humanos ${ }^{5}$. A atividade, por sua vez, é fundamental na obra de Leontiév e, por mais que seja posta em dúvida, ocupa igualmente lugar de destaque na Psicologia Histórico-Cultural, como afirma Vigotski em sua intervenção em um debate ocorrido em dezembro de 1933: "O fato central de nossa psicologia é o fato da ação mediada" (Vigotski, 1991a, p.130).

Segundo Duarte (2000), o conceito de atividade/ação utilizado tanto por Leontiév quanto por Vigotski parece estar diretamente relacionado ao conceito de trabalho humano, tal como proposto na teoria marxista ${ }^{6}$ :

(...) o trabalho é, para Marx, uma atividade que distingue o ser social do ser natural, isto é, define a especificidade do ser humano como um ser histórico, social e cultural, por possuir essas três características: a de ser uma atividade conscientemente dirigida por uma finalidade previamente estabelecida na consciência, a de ser uma atividade

5 A questão da mediação semiótica do psiquismo humano será desenvolvida neste mesmo texto.

6 Kozulin (1994) é um dos autores que discordam dessa interpretação. mediatizada pelos instrumentos e a de ser uma atividade que se materializa em um produto social, um produto que não é mais um objeto inteiramente natural, um produto que é uma objetivação da atividade e do pensamento do ser humano. (Duarte, 2000, p. 208)

Seguindo o referencial marxista, apresentam-se três aspectos fundamentais da atividade humana: a) ser orientada por um objetivo, b) fazer uso dos instrumentos de mediação e c) produzir algo que podemos caracterizar como elemento da cultura - seja por sua existência física seja por sua existência simbólica - e que consiste na objetivação do ser humano.

$\mathrm{O}$ primeiro destes aspectos (a) remete ao fato de que, se a atividade é orientada por um objetivo, supõese que seja consciente. A psique humana, no entanto, não se restringe à esfera da consciência, como destaca Vigotski:

(...)é preciso considerar esta (a psique) como parte integrante de um processo complexo que não se limita em absoluto a sua vertente consciente; por isso consideramos que na psicologia é completamente lícito falar do psicologicamente consciente e inconsciente: o inconsciente é potencialmente consciente (Vigotski, 1991a, p. 108).

Essa questão do consciente/inconsciente é complexa e merece ser aprofundada, porém extrapola o âmbito deste trabalho. Importante, no entanto, destacá-la, na medida em que apresenta a atividade como consciente ou não consciente, mediada ou imediata $^{7}$, sendo que o fator que as distingue é a utilização de instrumentos mediadores.

A mediação da atividade, segundo aspecto a ser ressaltado (b), foi desenvolvida por Vigotski (1991a, 1991b, 1991c), principalmente no que se refere aos signos enquanto instrumentos psicológicos produzidos socialmente e utilizados pelos seres humanos na comunicação com os outros com os quais se

7 De acordo com Vigotski, “(...) as relações entre as pessoas podem ser de dois tipos: mediadas e imediatas. São imediatas aquelas que se baseiam nas formas instintivas do movimento e da ação expressiva (automática e instintiva) (...) Em um nível superior de desenvolvimento aparecem, sem dúvida, relações mediatizadas entre as pessoas, cuja característica essencial é o signo, e que com sua ajuda se estabelece essa comunicação. Desse modo, a forma superior de comunicação - mediatizada pelo signo - cresce a partir das formas naturais de comunicação imediata: não obstante, elas se diferenciam, essencialmente, entre si" (Vigotski, 1987, p. 159). 
relacionam e consigo mesmos. Os signos são produto da ação do próprio ser humano e decorrem, portanto, da história da humanidade. Uma vez apropriados ${ }^{8}$, caracterizam o psiquismo humano como sígnico e, em conseqüência, inexoravelmente social. Sendo o signo 'um elemento que representa alguma coisa de alguma forma para alguém', a sua característica fundamental é a reversibilidade (Pino, 2000), isto é, o fato de representar algo tanto para quem o recebe quanto para quem o emite, o que não necessariamente coincide, posto que os sujeitos em relação atribuem sentidos diferentes àquilo que vivenciam.

Por fim, o terceiro e último aspecto diz respeito ao que é produzido em toda atividade humana, que produz cultura e, no processo dessa produção, objetiva o ser humano e ao mesmo tempo o subjetiva ${ }^{9}$ Ou seja, o resultado da atividade é tanto a produção de uma realidade humanizada quanto a humanização do sujeito que a empreende, em face da relação inexorável entre sujeito e sociedade que afirmamos no início deste texto.

Necessário se faz pontuar o fato de que em alguns momentos falamos em atividade e, em outros, em ação. Em Leontiév (1979) a distinção é clara: as ações humanas correspondem aos processos em que o objeto ao qual se dirigem e os motivos que a impulsionam não coincidem, sendo, portanto, partes constitutivas das atividades. Em Vigotski, no entanto, é destacado o conceito de ação mediada e não o de atividade ${ }^{10}$.

Além disso, demarca-se uma diferença fundamental entre as duas teorias, que resultam, apesar das suas aproximações, em perspectivas diferenciadas na explicação do psiquismo humano e, em decorrência, nas investigações psicológicas que se assentam nestes referenciais. $O$ ponto de separação refere-se ao que, da atividade ou ação, é apropriado

O conceito de apropriação é utilizado para referir-se ao processo de internalização, descrito por Vigotski (1991) como o movimento de transformação e incorporação, pelo sujeito, de algo que se processa nas relações interpessoais. A substituição dos termos se deve ao fato de que "o conceito de internalização veicula uma visão dualista e naturalista do homem e do social, a qual não corresponde à visão que deles tem o modelo histórico-cultural de psicologia" (Pino, 1992, p.316).

9 Sobre a dialética de objetivação/subjetivação, ver Maheirie (2002).

10 Essa distinção se faz necessária para demarcar outra diferença dos pressupostos de Vigotski em relação aos de Leontiév: enquanto para o primeiro o que é apropriado é a significação da realidade, Leontiév destaca a apropriação como “(...) interiorização das ações, isto é, a transformação gradual das ações exteriores em ações interiores, intelectuais" (Leontiév, 1979, p. 184). pelo sujeito. Leontiév (1979, p.184) destaca a "interiorização das ações, isto é, a transformação gradual das ações exteriores em ações interiores, intelectuais", e Vigotski pontua que o que é tornado próprio pelo sujeito é a significação ${ }^{11}$ da atividade/ação, aspecto este que desenvolverei no próximo item.

Caberia perguntar: há necessidade de utilizar, na investigação pautada nos referenciais vigotskianos, ambos os conceitos, de ação e atividade? A utilização do conceito de ação mediada não é suficiente?

\section{ATIVIDADE E AÇÃO: DA REALIDADE INVESTIGADA Å DEMARCAÇÃO DE REFERENCIAIS PARA PESQUISA}

$\mathrm{Na}$ pesquisa que realizei para a conclusão do doutoramento (Zanella, 1997), ao analisar os processos de ensinar e aprender a fazer renda de bilro, constatei que os aprendizes podem chegar a diferentes resultados, a saber:

a) A apropriação da(s) ação(ões) - entendida como a apropriação de partes da atividade como um todo. No caso da atividade analisada - aprender a fazer renda -, a apropriação da ação consiste na compreensão e possibilidade de confecção dos pontos da renda, mas isso não garante o domínio e a execução independente da atividade de confeccionar a renda de bilro; tampouco a possibilidade de criação de novas peças ou inovação do já conhecido.

b) A apropriação da atividade em si - envolve a apropriação do processo como um todo, o que possibilita ao aprendiz compreender e saber fazer os pontos, utilizando adequadamente os instrumentos mediadores da ação. É possível estabelecer relações entre as diferentes ações que a atividade compreende e seus instrumentos mediadores, consistindo assim em condição para a emergência do novo. Aqui se apresenta o sujeito em sua plena condição de autor, que parte de uma realidade conhecida e com ela dialoga, transformando-a e a si mesmo nesse processo.

A questão da mediação semiótica, fundamental na perspectiva vigotskiana, está presente tanto na

\footnotetext{
11 'A significação refere-se a 'o que as coisas querem dizer', aquilo que alguma coisa significa. Como as coisas não significam por si só, e nem tão pouco significam a mesma coisa para indivíduos diferentes, depreende-se que a significação é fenômeno das interações, sendo , pois social e historicamente produzida" (Zanella, 1997, p. 67).
} 
ação quanto na atividade. Apesar disso, a distinção entre estas me parece necessária, porque possibilita demarcar diferenças que remetem aos processos psicológicos envolvidos e às possibilidades para o sujeito: se a apropriação da ação caracteriza-se pelo saber-fazer (que na atividade em questão compreende o conhecimento dos nomes dos pontos da renda e a possibilidade de executá-los, sem que haja no entanto o domínio da sequiência de pontos sinalizada pelo instrumento mediador e/ou da articulação necessária entre os pontos), a apropriação da atividade envolve o compreender $e$ saber-fazer, onde as condições de execução somam-se à possibilidade tanto de ação independente quanto de criação. A apropriação da atividade pressupõe, nesse sentido, a apropriação do princípio de relação que caracteriza a dinâmica instrumentos/ações/objetivo a ser alcançado.

A apropriação da realidade é, portanto, na perspectiva vigotskiana, apropriação de uma relação semiótica que se origina na atividade, mas permite ao sujeito transcendê-la. Isso porque a leitura de relações múltiplas caracteriza a apropriação da atividade e a diferencia da apropriação da ação.

Que relações são estas? Relações que extrapolam os limites das ações em si e que as conectam com muitas outras, possibilitando a compreensão dos diversos elementos envolvidos, de outros possíveis e de como estes se relacionam. No caso da renda de bilro, apropriar-se da atividade significa saber fazer os vários pontos que permitem a confecção de diferentes modelos de renda, saber utilizar os diferentes instrumentos mediadores das ações e orientar o trabalho levando em consideração os modelos de renda culturalmente aceitos e valorizados, seja para reproduzi-los seja para confrontá-los. Aqui já estamos nos referindo ao terceiro aspecto anteriormente levantado, que caracteriza a atividade humana: o fato de esta produzir cultura e consistir em objetivação do sujeito que a empreende. Porém, esse processo de objetivação pressupõe ao mesmo tempo a subjetivação do sujeito, pois, ao apropriar-se da atividade, o sujeito apropria-se da história humana e imprime a esta sua marca.

O movimento de objetivação e subjetivação é possível graças à característica fundamental da atividade humana, isto é, o fato de ser mediada por signos. Estes, por sua vez, interligam o sujeito aos muitos outros com os quais se relaciona, sejam estes presentes - seus interlocutores - ou ausentes, referência esta à própria cultura humana objetivada nos signos, a qual lhes confere um caráter social e histórico.
$\mathrm{O}$ aspecto fundamental do signo, que lhe confere o caráter de nó górdio ${ }^{12}$ no processo de objetivação e subjetivação, é

(...) a propriedade de ser reversível, ou seja, a de significar tanto para quem o recebe quanto para quem o emite (...) O signo opera no campo da consciência, no qual ser autor e espectador constituem atributos de uma mesma pessoa. É por isso que a palavra dirigida ao outro produz efeito também naquele que a utiliza" (Pino, 2000, p. 59).

Via signos, portanto, a dupla direção da atividade humana se processa, pois na medida em que, por seu intermédio, o sujeito se objetiva e transforma a realidade, ao mesmo tempo transforma a si mesmo e se subjetiva.

Necessário ainda se faz destacar que, para Vigotski, o signo é apropriado pelo sujeito em sua significação. A relação que estabelecemos com a realidade é, neste sentido, sempre e necessariamente mediada pela cultura, pelos valores característicos do momento social e histórico em que vivemos, bem como pela nossa história de vida e o que, decorrente dela, consideramos significativo. Desse modo,

(...) toda a psique responde às características de um instrumento que seleciona, isola traços dos fenômenos. Um olho que tudo visse, precisamente por isto nada veria; uma consciência que se desse conta de tudo, não se daria conta de nada; se a introspecção tivesse consciência de tudo, não teria consciência de nada. Nossa consciência encontra-se encerrada entre dois limiares, vemos apenas um fragmento do mundo; nossos sentidos nos apresentam um mundo compendiado em extratos que são importantes para nós. (Vigotski, 1996, p. 284 - grifos nossos) ${ }^{13}$

A possibilidade de o sujeito atribuir sentidos diversos ao socialmente estabelecido demarca a sua

12 Utilizo aqui a metáfora do nó górdio para falar do signo porque é um tipo de nó praticamente impossível de desatar. Só há um ponto em que pode ser desfeito, todos os demais intensificam a amarração. No caso do signo, este definitivamente amarra os sujeito na trama da sociedade em que se insere, emaranhado este cuja origem dos fios não se identifica e que não se desfaz.

13 Nessa mesma direção, Thompson, ao falar sobre a cultura, afirma que "Os indivíduos não absorvem passivamente formas simbólicas mas, ativa e criativamente, dão-lhes um sentido e, por isso, produzem um significado no próprio processo de recepção" (Thompson, 1998, p. 201). 
condição de autor, pois, embora essa possibilidade seja circunscrita às condições sócio-históricas do contexto em que se insere, que o caracteriza como ator, a relação estabelecida com a cultura é ativa, marcada por movimentos de aceitação, oposição, confrontamento, indiferença.

$\mathrm{O}$ interesse em aprofundar essa questão, do sujeito em sua dupla dimensão - de quem produz história, é autor, e por esta é produzido, sendo ator -, levou-me a prosseguir a investigação anteriormente citada (Zanella, 1997), estabelecendo como foco de análise a constituição do sujeito e o/no processo de aprender a fazer renda de bilro. Uma das alunas que participaram da pesquisa anterior foi escolhida para tanto e, através de entrevistas, foi analisada a significação do ser-rendeira.

O contato com a atividade desde menina, o afastamento desta por vários anos e a reaproximação singularizam sua relação com o fazer-renda de bilro. $\mathrm{O}$ retorno à renda marca e é marcado pela sua história de vida, pois os olhares outros que desenvolveu em sua trajetória fazem com que o ato de aprender a confeccionar a renda de bilro seja pautado tanto pelo resgate do tecer tradicional, tal como vem sendo feito pelas mulheres de sua família, quanto pela necessidade de inovar, de transformar o produto da atividade, ainda que na tentativa de preservá-la (ver Zanella; Balbinot \& Pereira, 1999 e Zanella; Balbinot \& Pereira, 2000).

No diálogo travado com a atividade e os sujeitos que a têm como relevante em suas histórias de vida, a significação do "ser-rendeira" é transformada: a aprendiz de renda modifica um significado historicamente produzido porque este não mais atende à nova dinâmica de relações e práticas sociais que caracterizam o contexto no qual se insere. Desse modo, o domínio dos instrumentos é fundamental, porém a velocidade que caracteriza o tecer das rendeiras tradicionais não o é; saber tecer os modelos de rendas que há tempos vêm sendo mantidos é importante porque preserva a tradição, porém a estes acrescentam-se novas peças, que atualizam os produtos e possibilitam a difusão da renda e sua manutenção no contexto atual.

A relação que este sujeito estabelece com a atividade de fazer renda de bilro é, portanto, idiossincrática: ao mesmo tempo que procura mantê-la viva, que luta contra a sua extinção - o que a aproxima das rendeiras tradicionais - faz um movimento que a afasta do que está posto e insere novos movimentos à dinâmica das relações entre sujeitos, atividade e produtos que daí decorrem. Modificam-se nesse processo os próprios sujeitos, posto que, conforme apontado anteriormente, via atividade estes se objetivam e, ao mesmo tempo, com a apropriação de sua significação, constituem-se como singulares.

\section{CONSIDERAÇÕES FINAIS}

O relato destas investigações, ainda que breve, permite tecer considerações sobre a complexidade da pesquisa na perspectiva histórico-cultural, fundamentalmente as que têm como foco a "dimensão psicológica do ser humano". A este respeito Wertsch (1993) destaca que a análise dos mecanismos semióticos utilizados pelos homens nas atividades que empreendem constitui-se como foco para a investigação da ação mental humana. Mecanismos semióticos, por sua vez, são necessariamente sociais, históricos, institucionais, políticos e econômicos, o que significa considerar estas dimensões nas pesquisas com o referencial vigotskiano.

Smolka (2000), ao considerar que as ações são “inescapavelmente mediadas”, privilegia enfocar “(...) as significações da ação humana, os sentidos das práticas, considerando que todas as ações adquirem múltiplos significados, múltiplos sentidos, e tornam-se práticas significativas, dependendo das posições e dos modos de participação dos sujeitos nas relações" (Smolka, 2000, p. 31).

Ressalta-se portanto a necessidade de se analisar, na investigação pautada na psicologia históricocultural, as pessoas em atividades específicas considerando o movimento de significações (re)produzidas, transformadas e apropriadas em contextos sociais específicos. Destaca-se ainda que, por ser humana, a atividade pressupõe os muitos "outros" que caracterizam a cultura. Isto porque, em analogia à explicação de Bakhtin (1990) a respeito dos signos, a atividade necessariamente pressupõe um interlocutor, para o qual se dirige. É possível pensar também em vários interlocutores, pois há atividades que, aparentemente não endereçadas a ninguém, respondem a necessidades sociais características de um determinado momento histórico e, portanto, de coletividades anônimas.

Por outro lado, “(...) cada pessoa é em maior ou em menor grau o modelo da sociedade, ou melhor, da classe a que pertence, já que nela se reflete a totalidade das relações sociais" (Vigotski, 1996, p. 368). Olhar o específico - o sujeito - significa, considerando a afirmação de Vigotski, olhar o geral, a totalidade das relações das quais ele participa direta ou indiretamente, porquanto necessariamente estamos 
imersos em uma determinada forma de organização da vida que se objetiva nas práticas sociais, nos modos de ser, nos valores, enfim, nos signos que caracterizam a cultura capitalista ocidental. Tal tarefa é complexa, porém penso que pode ser levada a termo via análise do contexto no qual o sujeito se insere, das atividades que ele ali empreende, de sua condição histórica, do lugar que ocupa nesse contexto bem como do que ele significa e de como é significado pelos demais sujeitos com os quais se relaciona, o que se configura em expressão não de um sujeito em si, mas da própria história humana.

Sujeito, contexto, história, relações e lugares sociais são continuamente transformados como resultado da atividade dos próprios homens, o que nos leva a afirmar que a dimensão de processo e movimento permanente precisa necessariamente ser considerada, tanto no que se conclui quanto na forma como as análises são tecidas.

Essa é tarefa complexa: como olhar o específico, o contexto interpsicológico onde os sujeitos em relação (re)produzem, transformam-se e apropriam-se das significações das atividades que empreendem e, ao mesmo tempo, considerar as marcas históricas e sociais dos signos em trânsito que caracterizam esse contexto como ao mesmo tempo coletivo e singular? Como atentar para os aspectos econômicos, sociais e políticos que caracterizam a sociedade humana sem esquecer os espaços cotidianos em que esses são (re)produzidos, transformados e apropriados? Como olhar o geral, relacioná-lo com o específico e, por sua vez, olhar o específico considerando-o como expressão do geral?

Essas questões sinalizam para a complexidade do objeto de estudo em questão (no caso da investigação psicológica, a constituição do sujeito), o que requer, segundo Morin, um pensamento igualmente complexo:

(...) ou seja, um pensamento capaz de unir conceitos que se rechaçam entre si e que são suprimidos e catalogados em compartimentos fechados. Sabemos que o pensamento compartimentado e disciplinário ainda reina em nosso mundo. Este obedece a um paradigma que rege nosso pensamento $\mathrm{e}$ nossas concepções segundo os princípios de disfunção, de separação, de redução. Sobre a base desses princípios, é impossível pensar o sujeito e assim mesmo pensar as ambivalências, as incertezas e as insuficiências que há neste conceito, reconhecendo, ao mesmo tempo, seu caráter central e periférico, significante e insignificante (Morin, 1996, p. 55).
A constituição do sujeito enquanto objeto de estudo requer, portanto, o olhar sobre as condições sociais, históricas e econômicas em que este se insere e as características dos grupos sociais a que pertence. Ademais, a atividade mediada - que pressupõe as ações que esta compreende, igualmente mediadas e/em sua significação é categoria fundamental de análise, pois é através desta que o homem transforma o contexto social e, via apropriação de sua(s) significação(ões), constitui-se a si mesmo como sujeito.

Destaca-se deste modo a dimensão histórica da atividade, o que a caracteriza como manifestação cultural de um grupo social determinado que a executa/preserva/transforma e, nesse processo, também se modifica, bem como os sujeitos que dele participam. A explicação do psiquismo humano, sua gênese e processo de desenvolvimento só é possível, portanto, via análise da produção social da cultura e da produção cultural dos sujeitos.

\section{REFERÊNCIAS}

Bakhtin, M. (1990). ( $8^{\text {a }}$ ed.) Marxismo e filosofia da linguagem. São Paulo: Hucitec.

Duarte, N. (2000). Vigotski e o "aprender a aprender": crítica às apropriações neoliberais e pós-modernas da teoria vigotskiana. São Paulo: Cortez.

Ferreira, A.B.H. (1997). (2 ed. ${ }^{a}$ rev. e aum.). Novo dicionário da língua portuguesa. Rio de Janeiro: Nova Fronteira.

Kozulin, A. (1994). La psicología de Vygotski. Madrid: Alianza Editorial.

Leontiév, A. (1979). O desenvolvimento do psiquismo. Lisboa: Livros Horizonte.

Luria, A.R. (1979). Curso de psicologia geral (Vol. 1.) Rio de Janeiro: Civilização Brasileira.

Lyra, M.C.D.P.\& Moura, M.L.S.M. (2000). Desenvolvimento na interação social e no contexto histórico-cultural: adequação entre perspectiva teórica e metodologia. Psicologia: Reflexão e Crítica, 13,(2), 217-222.

Maheirie, K. (2002). Constituição do sujeito, subjetividade e identidade. Interações, 13 (7), 31-44.

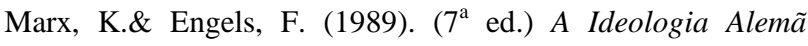
(Feuerbach). São Paulo: Hucitec.

Morin, E. (1996). A noção de sujeito. Em D.F. Schnitman (Org.), Novos paradigmas, cultura e subjetividade ( pp. 4555). Porto Alegre: Artes Médicas.

Neves, W.M.J. (1997). As Formas de Significação como Mediação da Consciência: um estudo sobre o movimento da consciência de um grupo de professores. Tese de Doutorado Não-Publicada, Programa de Pós-Graduação em Psicologia Social, Pontifícia Universidade Católica de São Paulo.

Pino, A. (2000). O social e o cultural na obra de Lev. S. Vigotski. Educação \& Sociedade, 21, (71),45-78. 
Pino, A. (agosto,1992). As categorias de público e privado na análise do processo de internalização. Educação $e$ Sociedade, XII (42), 315-327.

Rivière, A. (1985). La psicologia de Vigotski. Madrid: Visor Livros.

Smolka, A.L.B. (2000). O (im)próprio e o (im)pertinente na apropriação das práticas sociais. Cadernos Cedes, 20, (50), 26-40.

Thompson, J.B. (1998). ( $2^{\text {a }}$ ed.) Ideologia e cultura moderna: teoria social crítica na era dos meios de comunicação de massa. Petrópolis: Vozes.

Vigotski, L. S. (julho, 2000). Manuscrito de 1929.Educação e Sociedade,21(71), 21-44.

Vigotski, L.S. (1987). História del desarollo de las funciones psíquicas superiores. La Habana, Cuba: Ed. CientíficoTécnica.

Vigotski, L.S. (1991a). Obras escogidas I: problemas teóricos y metodológicos de la psicología. Madrid: Visor Distribuiciones.

Vigotski, L.S. (1991b). Obras escogidas II: problemas de psicología general. Madrid: Visor Distribuiciones.

Vigotski, L.S. (1991c). Obras escogidas III: problemas del desarollo de la psique. Madrid: Visor Distribuiciones.

Vigotski, L.S. (1996). Teoria e método em psicologia. São Paulo: Martins Fontes,.

Wertsch, J.V. (1988). Vigotski y la formación social de la mente. Barcelona: Ediciones Paidós.
Wertsch, J.V. (1993). Voces de la mente: un enfoque sociocultural para el estudio de la acción mediada. Madrid: Visor Distribuiciones.

Zanella, A.V. (1997). O ensinar e o aprender a fazer renda de bilro: estudo sobre a apropriação da atividade na perspectiva histórico-cultural. Tese de Doutorado NãoPublicada, Programa de Pós-Graduação em Psicologia da Educação, Pontifícia Universidade Católica de São Paulo.

Zanella, A.V.; Balbinot, G.\& Pereira, R.S. (1999). Tu me ensina a fazer renda que eu te ensino a ... inovar: um estudo do constituir-se rendeira à luz da psicologia históricocultural. Em A.F. Silveira et al. (Orgs.), Cidadania $e$ participação social (pp. 183-194). Porto Alegre: ABRAPSOSUL.

Zanella, A.V.; Balbinot, G.\& Pereira, R.S. (2000). A renda que enreda: analisando o processo de constitui-se rendeira. Educação \& Sociedade, 21, (71), 235-252.

Zinchenko, V.P. (1998). A psicologia histórico-cultural e a teoria psicológica da atividade: retrospectos e prospectos. Em J.V. Wertsch; P. Del Río; A. Alvarez (Orgs.), Estudos socioculturais da mente (pp. 41-55). Porto Alegre: ArtMed.

Recebido em 31/10/2003 Aceito em 12/03/2004
Endereço para correspondência:
Andréa Vieira Zanella, Universidade Federal de Santa Catarina - UFSC, Centro de Filosofia e Ciências Humanas - CFH, Pós-Graduação em Psicologia, Campus Trindade, CEP 88010-970, Florianópolis-SC. E-mail: azanella@cfh.ufsc.br 